\title{
Pulsed dye laser treatment of paediatric port wine stains - variation of practice in the UK (NHS)
}

\author{
Matthew Beattie $^{1}$ - Daniel Widdowson ${ }^{1} \cdot$ William Anderson ${ }^{1}$
}

Received: 6 January 2016 / Accepted: 19 January 2016/Published online: 9 February 2016

(C) Springer-Verlag London 2016

Port wine stains (PWS) are capillary vascular malformations affecting $0.3 \%$ of live births [1]. They appear as deep red/ purple flat patches of skin with well-defined borders. Their size and distribution can vary, and if left untreated, they can worsen with time, becoming darker and raised [2]. If present on the face or neck, the negative impact on the child's social, psychological, and economic development can be substantial $[3,4]$. Treatment of choice is by means of pulsed dye laser (PDL) [1], with the outcome aim being one of a reduction in size and colour intensity.

This study sought to quantify the variation of practice across the UK with regard to the PDL treatment of paediatric PWS, with focus given to the timing of treatment. A short questionnaire was sent via email and post, addressed to the lead clinician of all National Health Service laser unit centres. In total, 15 responses from 15 different centres were collected over a 7-month period (October 2014-April 2015).

The ideal age at which to commence treatment was most commonly given as 1 year old ( 7 of 13 valid responses). The other responses ranged from 1 month to 2 years old. The majority of respondents believed 'earlier treatment improves aesthetic outcome' ( 8 of 14 valid responses). Four respondents did not believe this, and two were unsure. Half of the respondents who did believe this provided an answer to the question 'At what upper age limit does earlier intervention make no

Matthew Beattie

matthew.beattie41@gmail.com

1 Department of Plastic Surgery, St John's Hospital, Livingston, NHS Lothian, Scotland difference to aesthetic outcome?' The answers given were 1, 13, 15, and 25 years old. Most commonly, on average, a course of treatment involved six separate sessions (6 of 10 valid responses) with 3-4 months of a time interval between treatments (10 of 14 valid responses). Some centres left only 2 months of an interval (3 of 14 valid responses), and one centre left 5 months. In general, all laser units use general anaesthesia (GA) in treatment of children under age 5 years old.

Of the 15 laser centres represented, $55 \%$ (16) of laser practitioners were consultant dermatologists and $45 \%$ (13) consultant plastic surgeons. Nine laser unit centres used the V-beam ${ }^{\circledR}$ Perfecta laser (Syneron-Candela ${ }^{\circledR}$ ), and six centres used Cynergy ${ }^{\mathrm{TM}}$ (Cynosure ${ }^{\circledR}$ ) laser.

The main conclusion from this study is that there exists a considerable variation in consensus and practice across the UK with regard to the timing of PDL treatment of paediatric port wine stains. It raises the question of whether national guidelines should be produced.

\section{References}

1. Chen J, Ghasri P, Aguilar G, van Drooge A, Wolkerstorfer A, Kelly K, Heger M (2012) An overview of clinical and experimental treatment modalities for port wine stains. J Am Acad Dermatol 67(2): 289-304.e29

2. Barsky S, Rosen S, Geer D, Noe J (1980) The nature and evolution of port wine stains: a computer-assisted study. J Investig Dermatol 74(3):154-157

3. Lanigan S, Cotterill J (1989) Psychological disabilities amongst patients with port wine stains. Br J Dermatol 121(2):209-215

4. Malm M, Carlberg M (1988) Port-wine stain-a surgical and psychological problem. Ann Plast Surg 20(6):512-516 